\title{
Iatrogenic Tracheal Ruptures: Review of the Literature and Personal Experience on 11 Cases $^{*}$
}

\author{
Bülent Aydemir ${ }^{1}$, Sezai Çelik ${ }^{1,2 \#}$, Oya Uncu ${ }^{1}$, Handan Tanrıkulu ${ }^{2}$, Tamer Okay ${ }^{1}$ \\ ${ }^{1}$ Department of Thoracic Surgery, Dr. Siyami Ersek Thoracic and Cardiovascular Surgery Center, Istanbul, Turkey; ${ }^{2}$ Department of \\ Thoracic Surgery, Haydarpasa Numune Training and Research Hospital, Istanbul, Turkey. \\ Email: \#dr_sezaicelik@hotmail.com
}

Received September $24^{\text {th }}$, 2013; revised October $24^{\text {th }}, 2013$; accepted October $31^{\text {st }}, 2013$

Copyright (C) 2013 Bülent Aydemir et al. This is an open access article distributed under the Creative Commons Attribution License, which permits unrestricted use, distribution, and reproduction in any medium, provided the original work is properly cited. In accordance of the Creative Commons Attribution License all Copyrights @ 2013 are reserved for SCIRP and the owner of the intellectual property Bülent Aydemir et al. All Copyright (C) 2013 are guarded by low and by SCIRP as a guardian.

\begin{abstract}
Objective: Iatrogenic tracheal rupture is a rare, but life-threatening complication of orotracheal intubation. In this retrospective study, etiology, and diagnostic and therapeutic approaches for iatrogenic tracheal ruptures were reviewed. Method: Eleven patients (6 males and 5 females) were diagnosed and treated for iatrogenic tracheal rupture in our clinic. The laceration occurred after orotracheal intubation in 7 cases, and during percutaneous tracheostomy and emergency tracheostomy in the other four cases, respectively. Diagnosis was made during thoracic surgery in 5 cases. The remaining cases were diagnosed in the post-operative period; the most common symptoms were mediastinal and subcutenous emphysema and pneumothorax. Results: The diagnosis was confirmed by bronchoscopy in all cases. The lacerations were longitudinal, $1-7 \mathrm{~cm}$ in length and were located in the distal membranous trachea. While ruptures detected intraoperatively were repaired during the surgery, the others were treated conservatively. No mortality was observed among cases treated surgically. However, three of the cases treated conservatively died (50\%), and the cause of death was the underlying disease requiring intubation. Conclusion: We are in the opinion that primary disease is a determinant of patient outcome. Except cases identified during surgery, emergency surgical interventions should be preferred in patients, in whom ventilation cannot be achieved. On the other hand, bronchoscopic fibrin glue instillation should additively be applied to conservative treatment of tracheal lacerations.
\end{abstract}

Keywords: Tracheal Rupture; Iatrogenic; Surgery; Conservative Treatment

\section{Introduction}

Iatrogenic tracheal ruptures are rare but life-threatening complications of orotracheal intubation [1,2]. The risk for iatrogenic tracheal lacerations is likely to increase with emergent or difficult intubations [1,3-5].

Although the reported incidence is very low, the true incidence is likely to be largely underestimated as the diagnosis may be missed in cases with indefinite clinical picture $[1,6]$.

In this retrospective study, 11 patients treated for iatrogenic tracheal rupture (ITR) were examined and evaluated for their etiology, prognostic factors and treatment strategies.

\footnotetext{
*Disclosure Statement: The authors have no financial or other interest in the manufacture or distribution of the device.

${ }^{\#}$ Corresponding author.
}

\section{Patients and Methods}

The study protocol was approved by the Ethics Committee of Dr. Siyami Ersek Thoracic and Cardiovascular Surgery Center and informed consents were obtained from patients except whose detected tracheal lacerations during primary surgery.

Eleven patients with ITR were diagnosed and treated in our clinic from January 2005 to October 2012. The medical records of the patients were retrospectively evaluated and discussed in the light of existing literature.Iatrogenic tracheal ruptures except surgically treated patients were diagnosed as follows: 1 ) Computed tomography of the chest (CT) for diagnosis of pneumothorax, pneumomediastinum, mediastinitis; 2) Fiberoptic tracheobroncoscopy for direct visualization of the whole trachea and main bronchi (performed by two experienced 
thoracic surgeon); and 3) Esophagoscopy to exclude an oesophageal lesion. Flexible bronchoscopy was performed at 10, 30, 90, 180 days in 8 patients who survived. Tracheal injuries due to blunt and sharp chest trauma were excluded from this study.

The demographic characteristics of the patients, the cause, location and extension of the rupture, clinical course, treatment and outcomes were analyzed.

\section{Results}

Totally, 6 men and 5 women with a mean age of 56 years (range, 10 to 79 years) were studied. ITR occurred after orotracheal intubation in 7 cases (doublelumen tube in 4 cases, single-lumen tube in 3 cases), during percutaneous tracheostomy in 2 cases and during emergency tracheostomy in 2 cases. The demographic and clinical characteristics of the patients are presented in Table 1.

The primary diseases for which surgery was performed were non-small cell lung cancer $(\mathrm{n}=1)$, plunging goiter $(\mathrm{n}=1)$, mediastinal mass $(\mathrm{n}=1)$, open pericardiectomy $(\mathrm{n}=1)$ and post-intubation tracheal stenosis $(\mathrm{n}=1)$. ITR occurred after percutaneous tracheostomy due to prolonged intubation in two patients, after failed intubation and emergency tracheostomy in one patient with pituitary adenoma, and after emergency intubation for cardiopulmonary arrest in two patients, and during stent removal in one patient. The causes and characteristics of the iatrogenic tracheal ruptures, treatment modalities and patient outcomes are shown in Table 2.

Table 1. Demographic and clinical characteristics of the patients.

\begin{tabular}{cl}
\hline Variables & Results \\
\hline Age (years) [mean (range)] & $56(10-79)$ \\
Gender (n) & 6 \\
Male & 5 \\
Female & \\
Etiology (n) & \\
Elective Intubation & 3 \\
Double Lumen & 3 \\
Single Lumen & 1 \\
Emergency Intubation (Double Lumen) & \\
Tracheostomy & 2 \\
Percutaneous & 1 \\
Surgical & 2 \\
Symptom (n) & 4 \\
Pubcutaneous Emphysema & \\
Mediastinal Emphysema & 2 \\
Pneumothorax & \\
\hline Subcutaneous & \\
\hline
\end{tabular}

Individual factors were; mediastinal shift due to deviation of the trachea in the patient with plunging goiter and mediastinal mass, neoadjuvant chemotherapy in the patient with lung cancer, long-term steroid usage in the patient with pericardial tuberculosis and emergency resuscitation for cardiac arrest in another.

Iatrogenic rupture was found during surgery in 5 cases, and after clinical and radiological investigations in 6 cases. One of the ITR cases found was the patient with plunging goiter in whom tracheal cuff of the doublelumen tube was herniated from a $5-\mathrm{cm}$ longitudinal tear in membranous trachea. A right posterolateral thoracotomy was performed and the rupture was detected during dissection of the mass.

The patient who underwent right upper lobectomy for a lung tumor was found to have mediastinal air leak. During exploration, a laceration extending to the proximal part of the left main bronchus was found in the distal membranous part of the trachea.

The patient who underwent pericardiectomy via sternotomy was detected to have mediastinal air leak. This patient was very difficulty intubated at first. A right posterolateral thoracotomy was performed and found in membranous part of the middle-lower trachea.

In the patient who underwent right thoracotomy for mediastinal mass, a rupture in the posterior membranous part of the middle-lower trachea developed during dissection about $3 \mathrm{~cm}$ longitudinally. In the patient who underwent surgery for tracheal stenosis, a longitudinal tear in the posterior membranous part of the trachea extending to the carina developed during intubation of the distal trachea after resection of the stenotic segment.

The clinical findings of the 7 cases diagnosed in the post-operative period were as follows, pneumothorax (n $=2)$, mediastinal and subcutaneous emphysema $(\mathrm{n}=2)$ and mediastinal emphysema $(n=3)$. Computed tomogramphy was performed in five patients and, a tear in the posterior membranous trachea was detected in 4 of them. The chest X-ray and computed tomography images of the patient with mediastinal and subcutaneous emphysema is presented in Figures 1(A) and (B). The definitive diagnosis was made by bronchoscopic evaluation. Esophagoscopy was performed in six patients to exclude concomitant esophageal lesion and there was no pathology in the esophagus.

The lacerations were all longitudinal and located in the distal membranous part of the trachea. Lengths of the lesions were $7 \mathrm{~cm}$ in 1 case, $5 \mathrm{~cm}$ in 3 cases, $2 \mathrm{~cm}$ in 2 cases, $3 \mathrm{~cm}$ in 3 cases and $1 \mathrm{~cm}$ in the others. In one case with a $7 \mathrm{~cm}$ rupture, the distal end of the lesion was extending to the proximal portion of the left main bronchus.

Surgical repair of the rupture was performed intraoperatively in the cases identified during surgery. After placement of the intubation tube distal to the laceration 
Table 2. The causes and characteristics of the iatrogenic tracheal ruptures, treatment modalities and patient outcomes.

\begin{tabular}{cccccccc}
\hline Case & Cause for Intubation & $\begin{array}{c}\text { Mechanic } \\
\text { Ventilation }\end{array}$ & Time of Diagnosis & Location of the Rupture & $\begin{array}{c}\text { Length of } \\
\text { the Rupture }\end{array}$ & Treatment & Results \\
\hline 1 & Pituitary adenoma surgery & No & 6 hours & Middle & $1 \mathrm{~cm}$ & Conservative & Survived \\
2 & Cardio-pulmonary arrest & Yes & 1 hour & Middle-lower & $5 \mathrm{~cm}$ & Conservative & Ex \\
3 & Cardio-pulmonary arrest & Yes & 1 hour & Middle-lower & $5 \mathrm{~cm}$ & Conservative & Ex \\
4 & Plunging goiter surgery & No & Intraoperative & Middle-lower & $5 \mathrm{~cm}$ & Surgical & Survived \\
5 & Tracheal stenosis surgery & No & Intraoperative & Middle-lower & $7 \mathrm{~cm}$ & Surgical & Survived \\
6 & Prostate cancer surgery & No & 4 hours & Middle & $1 \mathrm{~cm}$ & Conservative & Survived \\
7. & Lung cancer surgery & No & Intraoperative & Middle-lower & $3 \mathrm{~cm}$ & Surgical & Survived \\
8 & Tracheal stent removal & Yes & During procedure & Middle & $2 \mathrm{~cm}$ & Bio glue, chest drain Survived & Suld \\
9 & Mediastinal mass surgery & No & Intraoperative & Middle-lower & $3 \mathrm{~cm}$ & Surgical & Survived \\
10 & Pericardiectomy & No & Intraoperative & Middle-lower & $3 \mathrm{~cm}$ & Surgical & Survived \\
11 & Coronary bypass surgery & Yes & 2 hours & Middle-lower & $2 \mathrm{~cm}$ & Bio glue, chest drain & Ex \\
\hline
\end{tabular}

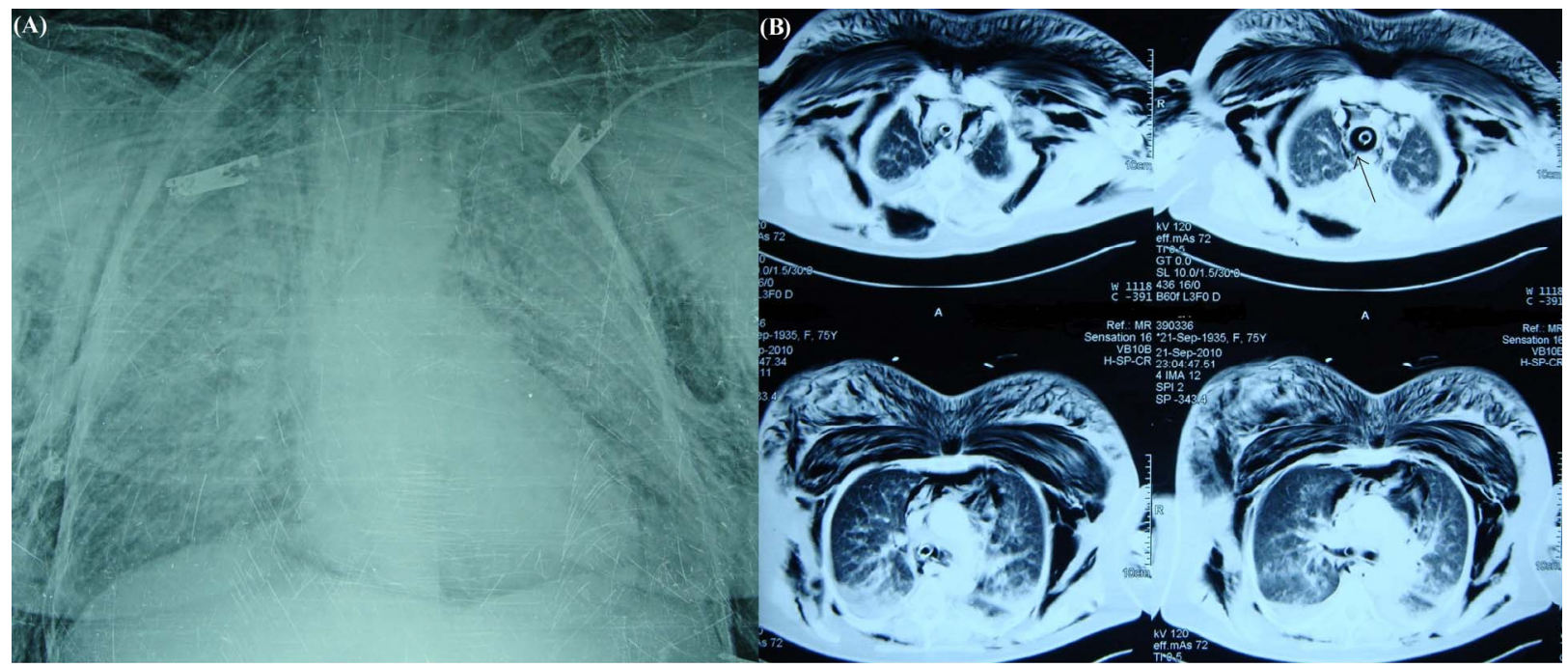

Figure 1. (A) Direct chest X-ray of a 48-year-old woman. In the chest X-ray obtained after intubation (single-lumen tube) for cardiopulmonary arrest, right main stem bronchus intubation and mediastinal emphysema is seen; (B) Computed tomography images of the same patient showing a laceration in the posterior membranous wall of the mid-trachea, mediastinal emphysema and diffuse subcutaneous emphysema (arrow).

for providing ventilation, primary repair was performed with continuous non-absorbable sutures.

The 6 patients diagnosed postoperatively were treated conservatively with broad-spectrum antibiotics, inhalation therapy and chest physiotherapy. Bronchoscopic instillation of fibrin glue was applied to two patients were treated conservatively. One of them was died owing to cerebrovascular attack. Three cases with between 1 - 2 $\mathrm{cm}$ tears in the middle part of the trachea were discharged at 8 days, 9 days and 11 days after diagnosis and their last bronchoscopic evaluation showed no tracheal rupture. The two patients had $5 \mathrm{~cm}$ laceration in the midle-lower part of the trachea. They were unconscious and their general condition was poor. They were treated with supportive care. Despite the improvement in ventilation, they died as a result of multi-organ failure unrelated to the tracheal injury. The patient underwent coro- nary artery by pass grafting surgery had $3 \mathrm{~cm}$ laceration and right subtotal pneumothorax. Fibrin glue instillation and chest drain treatment were successfully performed but the patient died from a serious cerebrovascular attack at postoperative day 5 .

Mean hospital stay 6.5 days. Morbidity included 2 atrial fibrillation and 1 pneumonia in three patients. Overall mortality was $27.2 \%$ in this series.

Flexible bronchoscopy at 10, 30, 90, 180 days showed complete healing among the 8 patients who survived.

\section{Discussion}

ITR is a complication of orotracheal intubation, percutaneous tracheostomy bronchoscopy and stenting of the trachea, and can lead to respiratory insufficiency and even death $[1,2,5]$. To our knowledge, 182 patients with ITR were reported in 50 publications in the last 40 years 
[5]. The incidence of ITR with single-lumen intubations and double-lumen intubations was reported to be $0.005 \%$, and $0.05 \%$ to $1 \%$, respectively $[2,7,8]$.

In recent years, the increase in the number of percutaneous tracheostomies in intensive care units and the use of general anesthesia in elderly patients has led to a higher incidence of ITR with each passing year. Anatomical, mechanical or personal factors may be responsible in the development of an ITR [5,9]. The etiological factors contributing to these injuries are, emergency intubations with stress situations, repeated attempts at intubation (difficult intubation), inadequate tube size (oversized tube), inappropriate intubation technique, overdistention or rupture of the cuff, malposition of the tube, strong cough while the expiration valve is closed, repositioning of the tube with the inflated cuff, and head and neck movements in intubated patients $[1,3,5,10,11]$. Anatomic abnormalities of the trachea, aortic aneurysm, disease causing distortion of the trachea, lung and mediastinum tumors, chronic obstructive pulmonary disease, inflammatory lesions of the trachea, chronic use of steroids, advanced age (over 50 years) and gender (being a woman) are the other reported risk factors [5,9]. Predisposing risk factors were emergency and difficult intubation, malposition of the trachea and inflammation of the tracheobronchial tree in our cases.

Early findings after trauma may be obscure. However, some clinical findings should raise the suspicion of tracheobronchial injury. The most often reported findings are sub-cutaneous emphysema, mediastinal and cervical emphysema, pneumothorax, hemoptysis and respiratory distress $[5,7,9,10]$. Pneumomediastinum and cervical emphysema are the most specific radiographic signs [12]. The incidence of pneumothorax ranges widely from 0 to $60 \%$ in reported cases [6]. Clinical presentation depends on whether the airway disruption communicates with the pleural space or is confined to the tissues of mediastinum. If the mediastinal pleura is intact, ventilation will not be affected. Although clinical signs occurred immediately or shortly after extubation, the time interval between the injury and the diagnosis was determined to be more than 24 hours, even 5 days in most of the previously reported series $[4,9,10]$.

Tracheobronchoscopy is the gold standard in establishing the diagnosis of post-intubation tracheal ruptures as well as tracheobronchial injuries [8]. This procedure is very important in determining the location and size of the injury and in planning the treatment strategy. Specific indications for bronchoscopy in tracheobronchial injuries are hemoptysis, pneumomediastinum, cervical emphysema and resistant pneumothorax after tube thoracostomy [12]. Computed tomography of the thorax is preferred to evaluate mediastinal emphysema, and pneumothorax in cases with severe subcutaneous emphysema and mediastinal hemorrhage [9]. Tracheal rupture is generally longitudinal and occurs in the membranous part of the trachea [5]. A consensus on the treatment of patients with ITR has not been reached yet. Treatment strategy depends on the clinical presentation and overall condition of the patient, and the etiology, location and size of the lesion $[7,13]$. Prognosis is mostly related to the underlying disease rather than the tracheal injury $[3,13]$. There is a consensus on the criteria for conservative treatment; the criteria for conservative treatment are stable vital signs, spontaneous breathing or no difficulty in ventilation while intubated or no respiratory distress after extubation, no evidence of esophageal injury, nonprogressive pneumomediastinum or subcutaneous emphysema and no signs of sepsis $[4,5,13]$.

The traditional method preferred by most authors for the management of ITR is primary repair $[10,13]$. The aim of surgical treatment is to maintain effective ventilation, to prevent secondary mediastinitis and to prevent secondary stenosis, especially in full thickness lacerations. However, after ITR, especially in the absence of concomitant esophageal injury, the risk of developing secondary mediastinitis and, tracheal stenosis is low $[13,14]$. The criteria for surgical repair of ITR include the following: lesions $>2 \mathrm{~cm}$. in length, perforation into the pleural cavity, progressive subcutaneous or mediastinal emphysema and insufficient mechanical ventilation [1,2]. However, some authors stated that surgical repair should be preferred only if the lesion was detected during a thoracic surgical procedure or in patients inadequately ventilated with mechanical ventilation $[1,13,15]$.

The approach mostly used for surgical repair is right posterolateral thoracotomy. For surgical repair in patients with a laceration of the upper or middle third of the trachea, transcervical approach can be preferred [2,3]. Nonabsorbable monofilament suture materials (polypropylene) are used more often but absorbable monofilament suture materials may also be used [15].

Surgical treatment was only performed in cases with lacerations incidentally detected during thoracic surgery. Six patients were treated conservatively. Three of them had small tears and their vital signs were stable. The other three patients had serious underlying diseases, and as the patients were at a high risk for extubation failure, surgical treatment was considered risky.

Patients, even those with extensive lacerations, can remain asymptomatic in the following situations: an intact mediastinal pleura, intubation with a long intubation tube and cuff herniation [16]. In the presence of cervical and mediastinal emphysema, tracheal rupture must be considered. Stylets should not be used in patients with anatomic abnormalities, tracheal stenosis, short neck, mediastinal shifts, or in patients treated with chemo-radiotherapy or has tracheal tissue damage resulting from any 
other reason. We believe bronchoscopy can decrease the risk of injury in double-lumen intubations in these patients.

One of the conservative therapies is bronchoscopic application of fibrin sealent onto the lesion. It may ensure tissue regeneration particularly in small tears $[14,17]$. We applied it two patients and air leak ceased and ventilation was improved.

\section{Conclusion}

We recommend concurrently surgical repair of the trachea when the tear is discovered during a thoracic surgery. Early surgical repair should be performed in patients who could not adequately ventilated. On the other hand, bronchoscopic fibrin glue instillation should be done additively to conservative treatment of small and short tracheal lacerations.

\section{REFERENCES}

[1] T. Schneider, K. Storz, H. Dienemann and H. Hoff- mann, "Management of Iatrogenic Tracheobronchial Injuries: A Retrospective Analysis of 29 Cases," Annals of Thoracic Surgery, Vol. 83, No. 6, 2007, pp. 1960-1964. http://dx.doi.org/10.1016/j.athoracsur.2007.01.042

[2] P. Borasio, F. Ardissone and G. Chiampo, "Post-Intubation Tracheal Rupture. A Report on Ten Cases," European Journal of Cardiothoracic Surgery, Vol. 12, No. 1, 1997, pp. 98-100. http://dx.doi.org/10.1016/S1010-7940(97)00111-5

[3] H. Ishibashi, S. Ohta, M. Hirose and T. Akimoto, "Blunt Tracheal Transection and Long Tear in Posterior Membranous Trachea," European Journal of Cardiothoracic Surgery, Vol. 30, No. 6, 2006, pp. 945-947. http://dx.doi.org/10.1016/j.ejcts.2006.09.009

[4] P. Carbognani, A. Bobbio, L. Cattelani, E. Internullo, D. Caporale, et al., "Management of Postintubation Membranous Tracheal Rupture," Annals of Thoracic Surgery, Vol. 77, No. 2, 2004, pp. 406-409.

http://dx.doi.org/10.1016/S0003-4975(03)01344-4

[5] E. Miñambres, J. Burón, M. A. Ballesteros, J. Llorca, P. Muñoz, et al., "Tracheal Rupture after endOtracheal Intubation: A Literature Systematic Review," European Journal of Cardiothoracic Surgery, Vol. 35, No. 6, 2009, pp. 1056-1062. http://dx.doi.org/10.1016/j.ejcts.2009.01.053

[6] S. Gabor, H. Renner, H. Pinter, O. Sankin, A. Maier, et al., "Indications for Surgery in Tracheobronchial Ruptures," European Journal of Cardiothoracic Surgery, Vol. 20, No. 2, 2001, pp. 399-404. http://dx.doi.org/10.1016/S1010-7940(01)00798-9
[7] A. Gómez-Caro, P. Ausín, F. J. Moradiellos, V. DíazHellín, E. Larrú, et al., "Role of Conservative Medical Management of Tracheobronchial Injuries,” Journal of Trauma, Vol. 61, 2006, pp. 1426-1434. http://dx.doi.org/10.1097/01.ta.0000196801.52594.b5

[8] L. Spaggiari, M. Rusca, P. Carbognani and P. Solli, “Tracheobronchial Laceration after Double-Lumen Intubation for Thoracic Procedures," Annals of Thoracic Surgery, Vol. 65, No. 6, 1998, pp. 1837-1839.

[9] H. S. Hofmann, G. Rettig, J. Radke, H. Neef and R. E. Silber, "Iatrogenic Ruptures of the Tracheobronchial Tree,” European Journal of Cardiothoracic Surgery, Vol. 21, No. 4, 2002, pp. 649-652. http://dx.doi.org/10.1016/S1010-7940(02)00037-4

[10] E. Miñambres, A. González-Castro, J. Burón, B. Suberviola, M. A. Ballesteros, et al., "Management of Postintubation Tracheobronchial Rupture: Our Experience and a Review of the Literature,” European Journal of Emergency Medicine, Vol. 14, No. 3, 2007, pp. 177-179. http://dx.doi.org/10.1097/MEJ.0b013e3280bef8f0

[11] C. H. Marty-Ané, E. Picard, O. Jonquet and H. Mary, "Membranous Tracheal Rupture after Endotracheal Intubation,” Annals of Thoracic Surgery, Vol. 60, No. 5, 1995, pp. 1367-1371. http://dx.doi.org/10.1016/0003-4975(95)00643-Y

[12] K. Gündüz and M. Yandi, "Isolated Tracheal Rupture Caused by Blunt Trauma and the Importance of Early Diagnosis: A Case Report," European Journal of Emergency Medicine, Vol. 11, No. 4, 2004, pp. 217-219. http://dx.doi.org/10.1097/01.mej.0000114646.63700.ef

[13] M. M. Rossbach, S. B. Johnson, M. A. Gomez, E. Y. Sako, et al., "Management of Major Tracheobronchial Injuries: A 28-Year Experience,” Annals of Thoracic Surgery, Vol. 65, No. 1, 1998, pp. 182-186. http://dx.doi.org/10.1016/S0003-4975(97)01001-1

[14] A. Wurtz, L. Benhamed, I. Hysi and M. Conti, "Endoscopic or Conservative Management of Postintubation Tracheal Membrane Laceration," Annals of Thoracic Surgery, Vol. 91, No. 5, 2011, pp. 1654-1655. http://dx.doi.org/10.1016/j.athoracsur.2010.11.044

[15] J. D. Richardson, “Outcome of Tracheobronchial Injuries: A Long-Term Perspective,” Journal of Trauma, Vol. 56, No. 1, 2004, pp. 30-36. http://dx.doi.org/10.1097/01.TA.0000108631.72315.78

[16] G. Frova and M. Sorbello, "Iatrogenic Tracheobronchial Ruptures: The Debate Continues,” Minerva Anestesiology, Vol. 77, No. 12, 2011, pp. 1130-1133.

[17] D. H. Sierra, "Fibrin Sealent Adhesive Systems: A Review of Their Chemistry, Materiel Properties and Clinical Applications,” Journal of Biomaterials Application, Vol. 7, No. 4, 1993, pp. 309-352. http://dx.doi.org/10.1177/088532829300700402 